$\therefore$

LA-UR-97-

$-4406$

Title:

PLASMA ARC MELTING OF ZIRCONIUM

$$
\begin{array}{r}
\text { CONF-97/168- } \\
\text { REPRIVED } \\
\text { JUL } 31999 \\
\text { OSTI }
\end{array}
$$

Author(s): $\quad$ PHILIP K. TUBESING, MST-6

DENIECE R. KORZEKWA, MST-6

PAUL S. DUNN, MST-6

Submitted to:

1997 INTERNATIONAL CONFERENCE ON TUNGSTEN, REFRACTORY METALS AND ALLOYS: PROCESSING, PROPERTIES, AND APPLICATIONS TO BE HELD AT ORLANDO, FL ON NOVEMBER 17-19, 1997 MASTER

DISTRABUTION OF THIS DOCUMENT IS UNLMMTED

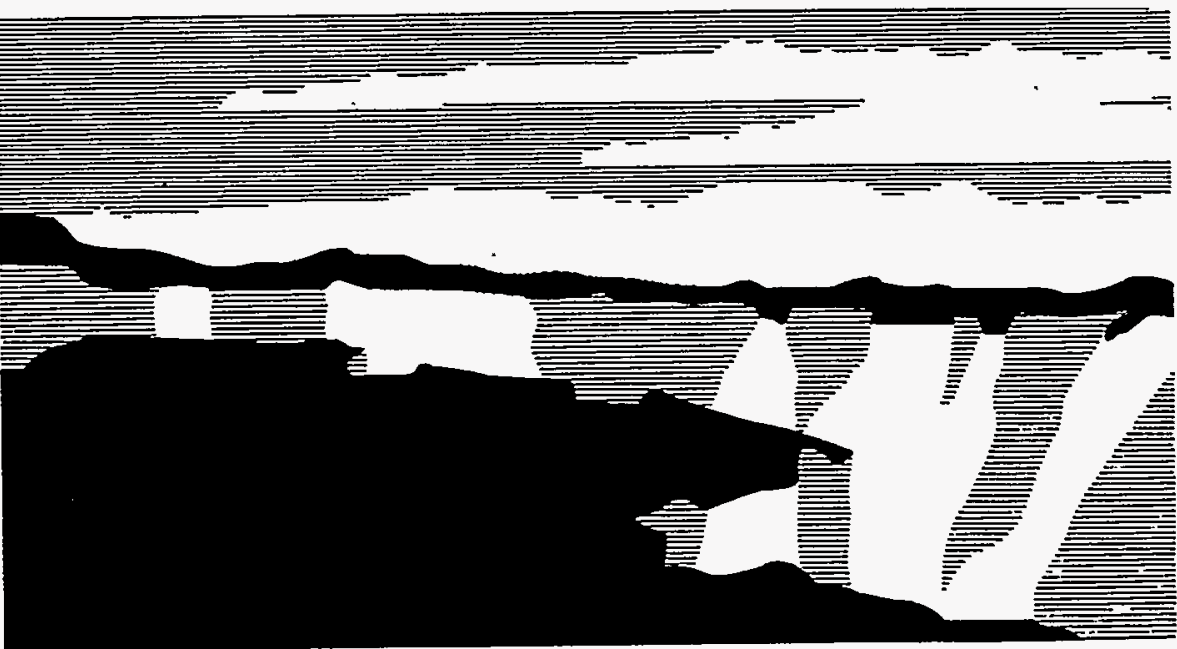

NATIONAL LABORATORY

Los Alamos National Laboratory, an affirmative actionequal opportunity employer, is operated by the University of California for the U.S. Department of Energy under contract W-7405-ENG-36. By acceptance of this article, the publisher recognizes that the U.S. Government retains a nonexclusive, royalty-free license to publish or reproduce the published form of this contribution, or to allow others to do so, for U.S. Government purposes. The Los Alamos National Laboratory requests that the publisher identify this article as work performed under the auspices of the U.S. Department of Energy. 


\section{DISCLAIMER}

This report was prepared as an account of work sponsored by an agency of the United States Government. Neither the United States Government nor any agency thereof, nor any of their employees, makes any warranty, express or implied, or assumes any legal liability or responsibility for the accuracy, completeness, or usefulness of any information, apparatus, product, or process disclosed, or represents that its use would not infringe privately owned rights. Reference herein to any spe- cific commercial product, process, or service by trade name, trademark, manufacturer, or otherwise does not necessarily constitute or imply its endorsement, recommendation, or favoring by the United States Government or any agency thereof. The views and opinions of authors expressed herein do not necessarily state or reflect those of the United States Government or any agency thereof. 


\section{DISCLAIMER}

Portions of this document may be illegible electronic image products. Images are produced from the best available original document. 


\title{
PLASMA ARC MELTING OF ZIRCONIUM
}

\author{
Philip K. Tubesing, Deniece R. Korzekwa, Paul S. Dunn \\ Materials Science and Technology Division \\ Los Alamos National Laboratory \\ Los Alamos, New Mexico 87545
}

\begin{abstract}
Zirconium, like some other refractory metals, has an undesirable sensitivity to interstitials such as oxygen. Traditionally, zirconium is processed by electron beam melting to maintain minimum interstitial contamination. Electron beam melted zirconium, however, does not responded positively to mechanical processing due to its large grain size. We undertook a study to determine if plasma arc melting (PAM) technology could be utilized to maintain low interstitial concentrations and improve the response of zirconium to subsequent mechanical processing. The PAM process enabled us to control and maintain low interstitial levels of oxygen and carbon, produce a more favorable grain structure, and with supplementary off-gassing, improve the response to mechanical forming.

\section{INTRODUCTION}

Traditionally, electron beam melting has been used for initial zirconium melt processing. This technique helps control the amounts of gettered contaminants such as oxygen and carbon. The disadvantage of our electron beam-melted zirconium was the large grain size that contributed to difficulties in further mechanical processing.

In general, plasma arc melting has the benefit of operating under a wide range of pressures (from vacuum to greater than atmospheric), varying the plasma feed gases, and producing finer grain structures. By the addition of reactive gases to the plasma stream, melt pool chemistry can be refined and modified to control the amounts of metallic and interstitial contaminants. Hydrogen is the obvious choice for a reactive plasma gas due to its high thermal conductivity, its affinity for combining with melt contaminants, and its relatively low cost. Mimura et al. ${ }^{[1]}$ have shown the benefits of PAM with hydrogen in the removal of contaminant alloying elements from scrap zircaloy. Their study used small amount of zircaloy (13 grams) and relatively long melt times (300 minutes). We were interested in much larger quantities and feed rates. Dunn et al. ${ }^{[2]}$ have shown the control of interstitials in much larger melt masses of tantalum (several kilos) and much shorter gas-metal interaction times. In this work the effect of shorter interaction time in zirconium is being studied.
\end{abstract}


Treco ${ }^{[3]}$ has shown in zirconium a correlation between increased oxygen concentration and both increased hardness and tensile strength and decreased ductility. We used hydrogen in our plasma stream to maintain or reduce the oxygen and carbon concentrations and minimize their embrittling effects. In this study, we used hardness as the measure of contaminant control. By returning the hardness of the melted material back to that of the starting crystal bar, we have kept the interstitial contamination low, and refined the grain structure to be more suitable for further mechanical processing.

\section{EXPERTMENTAL DETAILS}

This work was conducted in a Retech $150 \mathrm{~kW}$ single-gun plasma arc melter (schematic - Figure 1). The melt chamber is evacuated to approximately $50 \mu \mathrm{m} \mathrm{Hg}$, back-filled with argon, purged, then back-filled with argon again. Material is fed in from the side above the 4 inch $(10 \mathrm{~cm})$ diameter water-cooled copper crucible. The torch is manipulated by computer to melt and drip some of the feed stock into the melt pool contained in the crucible.

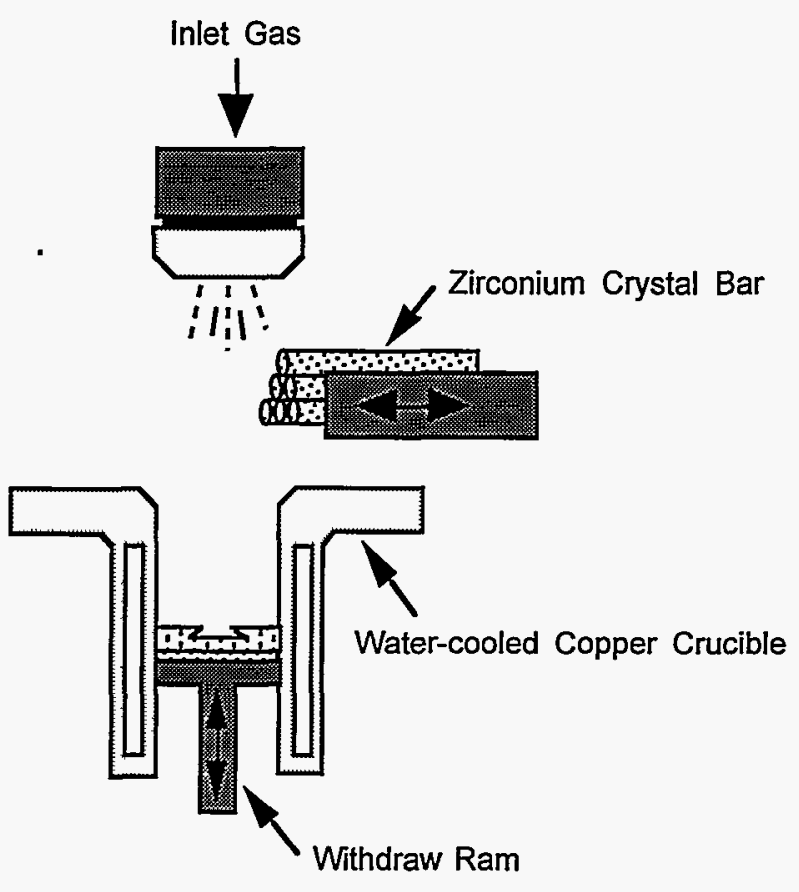

Figure 1 - Plasma Arc Melter Schematic

When an appropriate amount of material $(\approx 1$ inch pool depth) has been fed to the melt pool, the feed material is withdrawn and the torch pattern reset to work on the melt pool. The ingot can be withdrawn down through the crucible by hydraulic ram. Up to four separate feed gases can be mixed and used as the plasma medium. In this work we used a combination of ultra high purity argon and helium-6\%hydrogen mixed in roughly a $25 \% \mathrm{Ar}$ and $75 \% \mathrm{He}-6 \mathrm{H}$ mixture.

Two separate melts were performed for this experiment. After melting, hardness and metallography samples were taken from the ingots. Additional samples were vacuum annealed to remove the hydrogen from the zirconium. Hardnesses were taken of the starting crystal bar as well as the melted material before and after heat treatment to determine the levels of impurities.

Chemistry samples were not taken. 


\section{Zirconium Melt 1}

For the first melt, the plasma torch feed material was formed from six $15 \mathrm{~mm}$ diameter zirconium crystal bars $(\approx 7 \mathrm{~kg}$ total mass) bundled together with pure zirconium wire. The melt chamber was initially evacuated to $30 \mu \mathrm{m} \mathrm{Hg}$ then back-filled with argon. Feed gas was supplied at a pressure of $45 \mathrm{psi}(310 \mathrm{kPa})$ and a flow rate of $2.5 \mathrm{cfm}(70.8$ liters per minute). The gases were mixed approximately $1: 4$ with $0.6 \mathrm{cfm}(17 \mathrm{lpm})$ argon and $1.9 \mathrm{cfm}(53.8 \mathrm{lpm}) \mathrm{He}-6 \mathrm{H}$ making a effective hydrogen concentration in the feed gas $4.56 \%$.

The crucible withdraw mechanism failed early in the run and the melt had to be stopped after five minutes of melting. Even so, the zirconium melted quite easily and quickly. Approximately onethird $(2.2 \mathrm{~kg})$ of the feed material was melted. The ingot was halved axially and a $100 \mathrm{~g}$ sample was taken along the center line of the ingot. Half of this sample was prepared and submitted for hardness testing. The other half was annealed at $800^{\circ} \mathrm{C}\left(1472^{\circ} \mathrm{F}\right)$ for one hour. After annealing, this sample was also tested for hardness. The results of the hardness tests are shown in Table 1.

Table 1

Vickers hardness results from zirconium plasma melt \#1

(5kg load, 15 second dwell)

\begin{tabular}{|l|c|c|}
\cline { 2 - 3 } \multicolumn{1}{c|}{} & $\underline{\underline{\text { HV }}}$ & $\underline{\text { HRB }}$ \\
\hline Initial zirconium crystal bar & 70.8 & $<<40$ \\
\hline Zirconium after plasma melting \#1 & 105.3 & 55 \\
\hline Zirconium after heat treating & 73.1 & $<<40$ \\
\hline
\end{tabular}

Conversion to Rockwell B from Houk ${ }^{[4]}$

As shown in the table above, the hardness increased after exposure to hydrogen during melting and decreased after subsequent heat treatment. Conversions were made from Diamond Pyramid Hardness scale to Rockwell B for comparison. Rockwell B hardnesses for zirconium are not reported for values less than 40 (HV 90). The final hardness after heat treatment clearly is back to the hardness seen in the original crystal bar. This appears to confirm our hypothesis that plasma arc melting can maintain the amount of interstitial oxygen by replacing potential host sites with hydrogen in the feed gas. The embrittlement caused by the hydrogen is then removed by heat treatment.

\section{Zirconium Melt 2}

As with the first melt, the plasma torch feed material for the second melt was formed from six $15 \mathrm{~mm}$ diameter zirconium crystal bars $(\approx 6.5 \mathrm{~kg}$ total mass) bundled together. In this case the bars were 'welded' together in a non-consumable electrode arc melter before being loaded into the plasma melter. This was to help alleviate some difficulties with the feed mechanism during the first melt. The chamber was evacuated to $80 \mu \mathrm{m} \mathrm{Hg}$ then back-filled with argon. Feed gas was supplied at a pressure of $45 \mathrm{psi}(310 \mathrm{kPa})$ and a flow rate of $2.5 \mathrm{cfm}(70.8 \mathrm{lpm})$. The gas mixture was identical to Melt 1.

During this melt, there were few mechanical difficulties and the majority of the zirconium $(\approx 5.5$ $\mathrm{kg}$ ) was melted. Approximately 0.5 " $(12.7 \mathrm{~mm})$ of the outer diameter and ends of the ingot were 
machined off to leave a 3 inch $(76 \mathrm{~mm})$ diameter slug 3.5 inches $(89 \mathrm{~mm})$ long. A 0.25 " $(6.3 \mathrm{~mm})$ slice was taken off the end of the ingot and the slice halved to form two semicircles. Hardnesses were taken across the faces of both the ingot and both slices. The ingot and one slice were vacuum annealed at $800^{\circ} \mathrm{C}\left(1472^{\circ} \mathrm{F}\right)$ for 100 hours. Hardnesses were taken of the heat-treated ingot and slice. This hardness data as well as hardnesses taken from the electron-beam melted zirconium are shown in Table 2. The results are similar to plasma melt \#1 in that the hardness increases after plasma melting but decreases to initial levels after heat treatment.

Table 2

Rockwell hardness results from zirconium plasma melt \#2 (0.0625" (1.6mm) ball, $100 \mathrm{lb}$. (45.5kg) load)

\begin{tabular}{|l|c|c|c|}
\cline { 2 - 4 } \multicolumn{1}{c|}{} & $\underline{\text { HRF }}$ & $\underline{\text { HRB }}$ & $\underline{\text { Std Dev }}$ \\
\hline Zirconium after electron beam melting & 44 & -- & 6.3 \\
\hline 'Welded' zirconium crystal bar & --- & 45.1 & 8.5 \\
\hline Zirconium after plasma melting \#2 & 92.1 & 66.1 & 3.1 \\
\hline Zirconium after annealing & 86 & 51.1 & 10.4 \\
\hline
\end{tabular}

In comparison to the first melt, the hardness numbers in the second melt were significantly higher. This can be attributed to the 'welding' performed on the initial crystal bar. In additional melt tests, we found that processing zirconium in our non-consumable electrode arc melter caused hardnesses to increase dramatically, in one case hardnesses of HRB 85 were seen. We believe that during this pre-processing step, additional oxygen was gettered by the zirconium causing increased initial hardness. Even though the two melts differ in hardness values, it is clear that the plasma arc melting technique with subsequent heat treatment is an effective method to maintain interstitial oxygen contamination at low levels.

The end surfaces of both the plasma arc melted zirconium (Figure 2) and the electron-beam melted zirconium (Figure 3) were polished and etched. Each of the ingots are 3 inches $(76 \mathrm{~mm})$ in diameter and 3.5 inches $(89 \mathrm{~mm})$ long. As can been seen in the Table 3 and the following photo macrographs, the average grain size in the plasma melted material is approximately one-third that of the electron-beam melted material. There is also a greater than ten fold difference between the diameters of the finest plasma melted grains and the coarsest electron-beam melted grains.

Table 2 shows a significant difference in hardness between the electron beam melted zirconium and the plasma melted zirconium. Two factors certainly lead to this result. First, as previously stated, the initial feed material for PAM melt \#2 had a significantly higher hardness due to pre-processing. We do not have any characterization of the feed material used in the electron beam melter. It is quite possible that the electron beam melted ingot was processed from crystal bar of lower oxygen concentration than in either of the two plasma melts. In addition, hardnesses will tend to increase with grain refinement. Since the plasma melted ingot has a much finer grain structure, we would expect the hardnesses to be elevated when compared to the coarser grained material. 
Table 3

Average Grain Size Measurement

\begin{tabular}{|l|c|c|}
\cline { 2 - 3 } \multicolumn{1}{c|}{} & \multicolumn{2}{c|}{ Average Grain Size } \\
\cline { 2 - 3 } \multicolumn{1}{c|}{} & $\begin{array}{c}\text { ASTM Macro- } \\
\text { Grain Size } \\
\text { Number }\end{array}$ & $\begin{array}{c}\text { 'Diameter' of } \\
\text { Average Grain } \\
\text { Section }\end{array}$ \\
\hline Plasma melted zirconium & $\mathrm{M}-6$ & 0.18 " $(4.5 \mathrm{~mm})$ \\
\hline Electron-beam melted zirconium & $\mathrm{M}-3$ & $0.5 "(13 \mathrm{~mm})$ \\
\hline
\end{tabular}

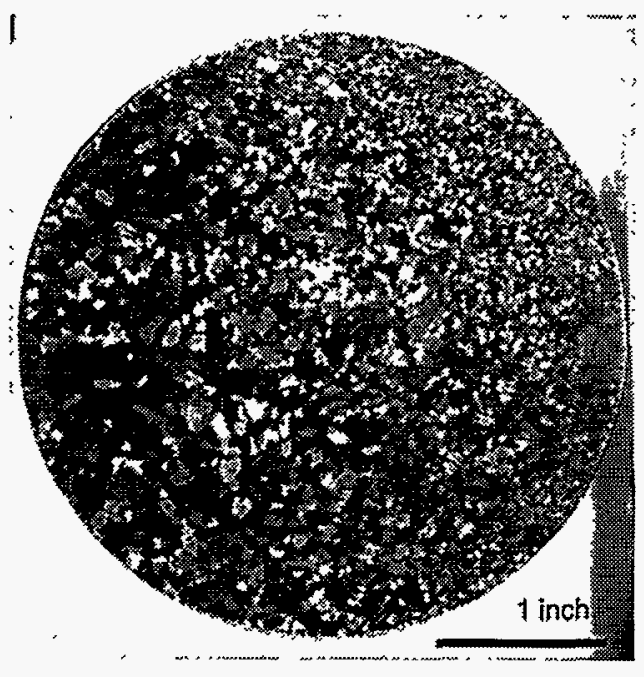

Figure 2 - Plasma arc melted $\mathrm{Zr}$

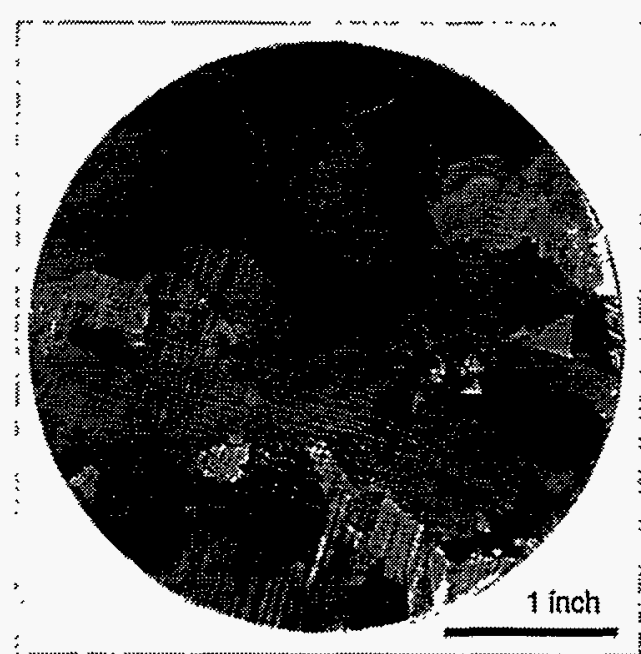

Figure 3 - Electron-beam melted $\mathrm{Zr}$

\section{CONCLUSION}

Based on hardness data, plasma arc melting provides an excellent alternative to electron beam melting for the processing of zirconium. Plasma melting offers the benefit of decreased gain size while maintaining the interstitial oxygen contamination at initial levels. Future development work on this topic include detailed chemistry analysis, parameter studies on the melting and heat treating, and response to mechanical forming.

\section{ACKNOWLEDGMENTS}

The authors wish to thank Fermin Garcia for excellent work with the plasma arc furnace and Terri Abeln for metallography and hardness data. Los Alamos National Laboratory is operated by the University of California under contract W-7405-ENG-36 with the United States Department of Energy who sanctioned this work.

\section{REFERENCES}

1. K. Mimura, S.W. Lee, M. Isshiki, "Removal of Alloying Elements from Zirconium Alloys by Hydrogen Plasma-arc Melting”, J. of Alloys and Compounds, 221, 1995, pp. 267-273. 
2. P.S. Dunn, D.R. Korzekwa, F.G. Garcia, "Chemistry Modification of High Oxygen-Carbon Powder by Plasma Melting", Tantalum, edited by E. Chen, A. Crowson, E. Lavernia, W. Ebihara, and P. Kumar, TMS, Warrendale, PA, February 1996, pp. 325-333.

3. R.M. Treco, "Some Properties of High Purity Zirconium and Dilute Alloys with Oxygen", Trans. Am. Soc. Metals, 45, 1953, pp. 872-892.

4. W.T. Houk, "Hardness Conversion Relationships for Zirconium and Zirconium-base Alloys", August 1953, Westinghouse Research Report R-94402-17-E, Westinghouse Corp., Pittsburgh, PA. 